\title{
Who has been driving the creation of industrial employment in Argentina? An analysis of the role of innovation
}

\author{
Mariano Pereira and Ezequiel Tacsir
}

\begin{abstract}
This paper analyses the relationship between innovation and job creation in firms. In particular, it seeks out data on the role played by innovation during the latest phase of expansion in Argentine manufacturing employment (2010-2012). It uses the model proposed by Harrison and others (2014), taking an instrumental variables approach and drawing data from the recently concluded National Survey of Employment Dynamics and Innovation (ENDEI). The results show that process innovations do not influence employment growth, but that this is positively affected by product innovations. The latter also enable production efficiency to be increased by more than it can with existing products. Where the composition of employment in terms of skills is concerned, product innovation is found not to present any particular bias.
\end{abstract}

\section{Keywords}

Employment, technological innovations, employment creation, industry, manufacturing enterprises, employment statistics, Argentina

JEL classification

D22, J23, 031

\section{Authors}

Mariano Pereira is a researcher and lecturer at the Institute of Industry (IDEI) of General Sarmiento National University (UNGS) and coordinates the Information, Monitoring and Evaluation Unit (UIME) of the Interdisciplinary Centre for Studies in Science, Technology and Innovation (CIECTI). Email: mpereira@ungs.edu.ar or lic.mpereira@gmail.com.

Ezequiel Tacsir is a senior researcher with the Centre for Economic Research (CINVE) and the United Nations University-Maastricht Economic and Social Research and Training Centre on Innovation and Technology (UNU-MERIT). Email: tacsir@cinve.org.uy. 


\section{Introduction}

Employment in Argentine manufacturing industry has followed a path characterized by phases of very deep contractions and strong expansions. Between 1998 and 2001, when the economy was moving towards an abrupt exit from the currency board regime, formal private sector employment contracted by an average of $5 \%$ a year. In 2002, following devaluation of the Argentine peso, industrial employment went through a phase of strong expansion, with increases averaging $8.5 \%$ a year. During 2009 , in the midst of the international financial crisis, there was a large decline $(2.2 \%$ a year) in the number of jobs. The recovery following the contraction was short-lived but steep: from 2010 to 2012, employment increased by an average of about 3\% a year. Lastly, industrial employment has shown no signs of resuming growth since 2013, but has been remarkably stagnant.

The above description leaves room for analysis of the determinants of this performance. In particular, it invites questions about the role played by innovation as a driver of employment. The lack of microdata at the individual firm level formerly made this impossible to investigate. The publication of the National Survey of Employment Dynamics and Innovation (ENDEI), however, has provided an extremely useful tool for answering this and other questions. In particular, the database has allowed attention to be focused on the latest period of expansion in industrial employment (2010-2012) and the following questions to be answered: (i) what effect do the different types of innovation (product, process, organizational change) have on employment (job creation or displacement)? (ii) how are different effects on firms of different sizes and in different sectors (potentially) produced? (iii) do the different types of innovation affect employment quality (skills composition)?

To answer all this, it is necessary to distinguish between the different innovations introduced in firms and their influence on employment via multiple channels. The literature identifies four types of innovation: process, product, marketing and organizational. The debate centres on the first two, which are those considered technological in nature. The purpose of this article is to understand the impact of technological innovations on employment in Argentine manufacturing firms during the latest phase of expansion. It proposes to follow the methodology developed by Harrison and others (2014). This model, hereinafter called the Harrison and others (2014) model, has been employed in most empirical studies carried out with firm-level microdata in recent years.

The article is organized as follows. After this introduction, the second section analyses the relationship between innovation and employment from a theoretical perspective, expanded by a review of the literature on Argentina. The third section expounds the methodological strategy, setting out by presenting the Harrison and others (2014) model and paying special attention to issues related to difficulties with the identification strategy and the need to implement estimates based on instrumental variables (IV) in order to obtain consistent results. The fourth section presents the information used and the main characteristics of the firms, together with their behaviour during the period under analysis. The fifth presents the effects of innovation on employment growth at the firm level. The sixth and seventh sections also expand these results by determining the impact on employment by skill type and break down employment growth into its main factors. Lastly, the eighth section contains conclusions and implications relevant to policy design.

\section{The complex relationship between innovation and employment growth}

The discussion about the effects of innovation processes (at both the firm level and the aggregate level) on employment is both long-standing and complex (Yoguel, Barletta and Novick, 2013). The effect of innovation is contingent on the level of analysis (direct effects at the firm level and sectoral or 
economy-wide indirect effects), transmission mechanisms, institutional aspects and feedback (Pianta, 2006; Vivarelli, 2011). Again, these effects are bound to depend on the technology in use and the impact of these innovations on productivity, as well as on demand conditions. Thus, a variety of compensation mechanisms can be observed. ${ }^{1}$

Similarly, innovation may generate dissimilar effects at the sectoral level, depending on the reaction of other firms to innovations in their sector of activity. Thus, it is possible to envisage redistribution of production and employment levels (loss of market share, comparable to the process of creative destruction) from less innovative to more innovative firms. There may also be situations such as the destruction of jobs due to the withdrawal of non-innovative firms or, conversely, the creation of new firms and jobs (spin-offs) that can exploit the opportunities opened up by the innovations concerned. The final outcome in the sector (i.e., the sum of employment in innovative and non-innovative firms) will depend on the elasticities of substitution within each sector and between different sectors. In this connection, Greenan and Guellec (2000) find, first, that product-innovating firms create more jobs than non-innovating ones and that these sectors as a whole are more dynamic. Second, process innovation, while generating employment at the firm level, has the opposite effect at the sectoral level. Lastly, there may be different effects at the general equilibrium level, depending on the interaction between different markets. Simply put, the speed and responsiveness with which innovators meet increased demand will depend on how quickly other industries can provide the required inputs. At the same time, innovation can affect employment through complementarities in the consumption of goods, increases in variety or improvements in the quality of intermediate inputs. Lastly, the introduction of new products can boost the creation of new economic activities.

Various aspects associated with the characteristics of the productive sector and innovation determinants and behaviour imply that the above-mentioned results cannot be automatically extrapolated to countries such as Argentina. Indeed, knowledge embodied through the acquisition of machinery and equipment (often via international trade) plays an important role, as does technology transfer. Technology and production processes designed for conditions in more developed economies, where innovations are often aimed at improving efficiency in the use of labour (deemed relatively scarce), may not be perfectly adaptable to the context in question, as they will have different effects on employment and its composition. At the same time, the objectives and scope of the innovation process, often oriented towards the adaptation and imitation of products and processes developed at the production frontier, can reinforce these differences.

At the same time, the production structure is characterized by a greater presence of SMEs, whose routines and ability to innovate are often based on informal processes, the acquisition of technology rather than investment in intangibles such as research and development (R\&D) and a greater focus on less sophisticated markets. Similarly, low-technology manufacturing activities dominate employment and production. With these characteristics, there tend to be lower levels of highly skilled human resources and a preponderance of process innovations over product innovations. Since the prevalence of the different types of innovation may differ between sectors, these effects can be expected to exhibit sectoral heterogeneity. At the same time, it is possible that labour regulations, together with the prevalence of informal working, may affect companies of different sizes in different ways. ${ }^{2}$ Consequently, this study will pay special attention to the effects associated with various sectoral groupings (according to their levels of labour informality and technological intensity) and to differences attributable to company size.

Diagram 1 summarizes the displacement and compensation mechanisms characterizing the relationship between innovation and employment growth.

\footnotetext{
1 This applies to both process and product innovations. While process innovations can displace employment in the short run, it is reasonable to expect employment to increase in the long run as productivity gains manifest themselves in lower prices to which consumers react. The opposite may occur in the case of product innovations. With the latter, changes in the demand for new goods or services may cause competition to increase, with imitators exercising a compensation effect.

2 Informal working is a complex, multidimensional and multifaceted phenomenon. Throughout this article, it will be deemed equivalent to non-registration of wage employment in the social security system.
} 
Diagram 1

Process and product innovation mechanisms and employment effects

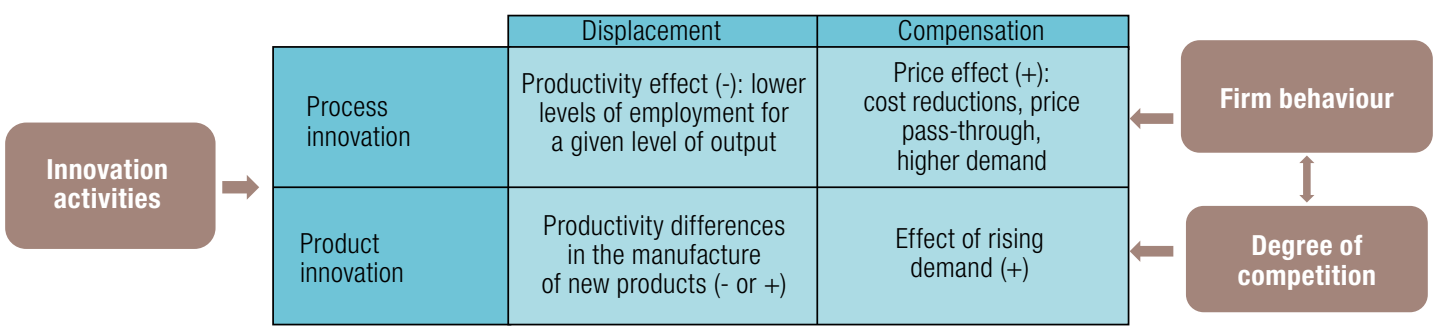

Source: Prepared by the authors, on the basis of R. Harrison and others, "Does innovation stimulate employment? A firm-level analysis using comparable micro-data from four European countries", International Journal of Industrial Organization, vol. 35, Amsterdam, Elsevier, 2014; and G. A. Crespi and E. Tacsir, "Effects of innovation on employment in Latin America", MERIT Working Papers, No. 1, Maastricht, United Nations University-Maastricht Economic and Social Research Institute on Innovation and Technology (UNU-MERIT), 2013.

As stated earlier, the objective of this study is to determine the role played by the generation of innovations during the latest phase of expansion in industrial employment in Argentina (2010-2012). Within this framework, the theoretical procedure allowed the following research questions to be specified: (i) how strong were the compensation and displacement effects? (ii) what ultimately was the balance between them? (iii) do the results change when sectoral and size specificities are taken into account? (iv) was innovation skewed towards opportunities for creating more highly skilled jobs?

\section{Empirical background}

The literature review shows that few studies have analysed the effects of innovation on the quantity and quality of employment in Argentina. This striking dearth is largely explained by the lack of firm-level microdatabases in the post-convertibility phase. Almost all the studies that do exist analyse the 1990s.

The earliest study is Albornoz (2002), which uses the technology surveys of the first half of the 1990s and finds that the employment substitution effect was stronger than the effect of the complementarities generated. The author argues that this is because the innovation capacity of firms centred more on embodied than on non-embodied innovation efforts. In particular, the positive effects of automation and cost rationalization on employment failed to balance the negative effects of product, process and organizational innovations. The author also analysed the impact of these variables on employment by skill level and showed that innovation did not influence changes in skill requirements.

The study by Roitter, Erbes and Trajtemberg (2007) analyses the relationship between innovation and employment in a group of companies in the Argentine metallurgy sector. The authors argue that during the convertibility crisis (1998 to 2001) the intensity of the innovation process was not associated with changes in employment, which shows how central the cycle is in explaining this variable. The panel analysis reveals that the most innovation-intensive firms in 1992-1996 contributed 13\% more employment during the period 1992-2001.

De Elejalde, Giuliodori and Stucchi (2011) estimate the Harrison and others (2014) model with a sample of manufacturing firms obtained from a single survey in 2003 containing retrospective information on the state of the firms for each year since 1998-2001. According to their results, there are no significant data demonstrating the impact of process innovation on employment in those years. As regards product innovation, there were no significant efficiency differences between the production of new and old goods. In decomposing employment growth, they therefore conclude that there is no evidence of a displacement effect resulting from the introduction of product innovations. Employment was only created because of increased demand for older products. Nor do they find that process innovation affects employment, since that type of innovation did not lead to large productivity gains. 
Lastly, the only study to move forward into the post-convertibility stage is Yoguel, Barletta and Novick (2013), using a database developed by splicing the records of the Integrated Retirement and Pension System and the SME activity monitoring survey of the Ministry of Labour, Employment and Social Security (MTEySS). The study finds that innovation efforts and intensity both increased the likelihood that firms would achieve high employment growth rates. The positive association of innovation process inputs and outputs with employment dynamics meant that, for the first time, productivity gains were not associated with restructuring processes involving job losses.

\section{Methodological strategy}

\section{The Harrison and others (2014) model: innovation and employment growth}

To try to distinguish between the displacement effect and the compensation effect with firm-level data, most empirical studies of recent years have used the methodology developed in Harrison and others (2014). This model includes the estimation of some structural parameters and proposes alternative instruments for solving the problem of endogeneity in covariates.

Harrison and others (2014) show that, to separate the potential employment growth effect due to innovation from that associated with displacement due to the changes made, it is helpful to distinguish between product innovations and process innovations. This article takes the same starting point and differentiates between two types of products: existing products manufactured at the start of the period and new products. Thus, employment growth is broken down into one part associated with improvements in the efficiency of existing products (resulting from process, organizational and commercial innovations with potential labour displacement and any compensation mechanisms associated with increased market size due to a reduction in the prices of these products) and another associated with the introduction of products (product innovation).

Consequently, it may be supposed that a firm can produce two types of products: "existing products" and "new products". Production of these at time $t$ is denoted $Y_{1 t}$ and $Y_{2 t}$, respectively. The information available allows each individual firm to be observed at two different points in time: the start of the period $(t=1)$ and the end $(t=2)$. The initial assumption is that each type of product is created with an identical and separable production function, with constant returns to scale. ${ }^{3}$ Each technology has an efficiency parameter $\left(\theta_{i t}\right)$ which changes over time. New products may be manufactured with higher or lower levels of efficiency than existing products, and firms can influence production efficiency by means of process (and organizational) innovations. The cost function at time $t$ can be written thus:

$$
C\left(w_{1 t}, w_{2 t}, Y_{1 t}, Y_{2 t}, \theta_{1 t}, \theta_{2 t}\right)=c\left(w_{1 t}\right) \frac{Y_{1 t}}{\theta_{1 t} \mathrm{e}^{\eta+\omega_{1 t}}}+c\left(w_{2 t}\right) \frac{Y_{2 t}}{\theta_{2 t} \mathrm{e}^{\eta+\omega_{2 t}}}
$$

where $c(w)$ is a function of input prices. Firms' productivity is affected by a specific unobservable component of fixed effects and shocks ( $\eta$ and $\omega$, respectively). The term $\eta$ captures all factors that affect productivity but remain constant over time (e.g., the best management skills and motivation), while $\omega$ captures shocks that vary over time in their effects on production (e.g., energy shocks, labour disputes and conflicts, and unforeseen problems). According to Shephard's lemma, the conditional demand for labour in the manufacture of each of the products is:

3 De Elejalde, Giuliodori and Stucchi (2011) propose similar exercises for other production functions. 


$$
L_{i t}=C_{L}\left(w_{i t}\right) \frac{Y_{i t}}{\theta_{1 t} e^{\eta+\omega_{i t}}}
$$

where $C_{L}(w)$ is the derivative of $c(w)$ with respect to wages. The starting assumption is that $C_{L}(w)$ remains constant in the reference period and that it is identical for the manufacture of each type of product. ${ }^{4}$ In this case, the employment growth rate at the firm level is given by the rate of employment growth in the manufacture of existing products plus the rate for the manufacture of new products. If it is assumed that no new products are created at the start of the period $\left(Y_{21}=0\right)$, employment growth can be approximated as:

$$
l=\frac{\Delta L}{L}=-\left(\frac{\theta_{12}-\theta_{11}}{\theta_{11}}\right)+\left(\frac{Y_{12}-Y_{11}}{Y_{11}}\right)+\frac{\theta_{11}}{\theta_{22}} \frac{Y_{22}}{Y_{11}}-\left(\omega_{12}-\omega_{11}\right)
$$

This expression indicates that employment growth is the result of change in the efficiency of the production process for existing products, the rate of change in these products and growth attributable to new products. These efficiency gains can be expected to be greater for firms that introduce process innovations associated with existing products (i.e., without product innovations). Again, the effect of product innovation will depend on the difference in efficiency levels between the processes for existing products and new products. If new products were manufactured more efficiently, this ratio would be less than 1 and the growth rate would not be the same as for the product in question owing to the introduction of these new products. Equation (3) therefore suggests the following regression to estimate the effects of innovation on employment:

$$
l=\alpha_{0}+\alpha_{1} d+y_{1}+\beta y_{2}+v
$$

where $l$ is overall employment growth, $y_{1}$ is the real rate of growth in sales of existing products, $y_{2}$ is the real rate of growth in sales of new products and $d$ captures the introduction of process innovations in the manufacture of existing products. The error term, $v$, captures productivity shocks. Generally speaking, it seems reasonable to think that the introduction of process innovations tends to displace employment, while product innovations tend to create employment, except when new products replace existing products and those new products are characterized by greater efficiency than the existing products. ${ }^{6}$

\section{Identification strategy}

The correct identification of equation (4) can be affected by two problems: the possible endogeneity of the innovation variables and the measurement errors generated by using sales at current prices rather than actual sales as regressors. With regard to endogeneity, consistent estimation of (4) requires non-correlation of the variables representing process and product innovations with the error term. Innovations are the result of investment decisions that companies should make in advance. These

4 This is the case if relative prices do not change much over time or between existing products and new products.

5 To simplify, this sets out from the assumption that $w_{11} \sim w_{22}$.

6 Real growth in sales of existing products ( $y 1)$ is the outcome of three different effects: (i) the autonomous increase in demand for existing products experienced by the firm, (ii) the compensation effect induced by price changes after the introduction of process innovations and (iii) the substitution effect resulting from the introduction of new products. Since it is not possible to separate these components without more information, in practice $y 1$ will simply be subtracted from I, so an alternative specification of equation (4) is to use the inverse of labour productivity growth as a dependent variable. 
decisions depend on the productivity of the firm, which can be characterized as an unobservable element composed of two factors: attributes of the firm that are fairly constant over time (e.g., management skills, shown as $\eta$ in the above expressions) and productivity shocks ( $\omega$ ). If investments in innovation are correlated with productivity, so are the results. Consequently, the results of innovation are endogenous, which creates a serious identification problem.

Since equation (4) is specified as the real growth rate, it is to be expected that the specific components (fixed effects) of the firm have been removed from the error term. The correlation between innovative products and productivity shocks, meanwhile, will depend on when investment decisions are made. If adopted in advance of shocks (even if there is a delay between decision-making and investments actually being made), the variables related to innovation in equation (4) will not be correlated with the error term and it will be possible to estimate the equation using the ordinary least squares (OLS) method. ${ }^{7}$ However, if investment decisions are taken at the same time as productivity shocks occur, the innovation results may be endogenous in equation (4).

In this case, it is interesting and informative to explore the direction of the bias. If process innovations (d) were positively correlated with productivity shocks in the manufacture of existing products in the second period $\left(\omega_{12}\right)$, the fact that these shocks enter into the error term preceded by a minus sign in (4) means that the correlation should be negative. Thus, the OLS estimation will tend to overestimate the displacement effect or underestimate any compensation effect due to innovation. At the same time, a negative correlation with the error term is also to be expected in the case of product innovations. This means that the OLS method will underestimate the true impact of product innovation on employment growth. Consequently, the impacts estimated by means of OLS are to be interpreted as a "lower bound" to the ratio between these two variables.

The identification of this ratio will depend on the availability of appropriate instruments (i.e., instruments correlated with the innovation variables but not with the error term). Although innovation surveys provide a number of variables that can be used as instruments, the great majority are more suitable for identifying product innovation than process innovation, which has more idiosyncratic characteristics. It should be mentioned that most of the companies that report having introduced product innovations have done so in combination with process innovations ("coinnovation"). For empirical purposes, these firms are considered to be product innovators. The number of firms that only introduce process innovations (i.e., without product innovations) is small. For that reason, even considering the negative bias described above, their influence can be expected to be marginal. Consequently, empirical implementation will focus on obtaining reliable estimates for product innovations, on the assumption that process innovations tend to be exogenous. ${ }^{8}$

A second source of endogeneity is the presence of measuring errors. Ideally, equation (4) should contain information about real-term production of existing products $\left(y_{1}\right)$ and new products $\left(y_{2}\right)$. Instead, all it contains is nominal sales growth $\left(g_{1}\right.$ and $\left.g_{2}\right)$, as firm-level prices are not available. For both products, current sales growth can be decomposed into two terms: real growth and price changes. In other words, $g_{1}=y_{1}+\pi_{1}$ for existing products and $g_{2}=y_{2}+\pi_{2}$ for new products. If these two expressions are substituted into (4) and nominal sales growth for existing products is moved to the left of the expression, the result is:

$$
l-g_{1}=\alpha_{0}+\alpha_{1} d+\beta g_{2}+\left(-\pi_{1}+\beta \pi_{2}+v\right)
$$

\footnotetext{
7 These are the type of investment decisions found in Olley and Pakes (1996).

8 There are good reasons to think that process innovations are indeed exogenous. As Harrison and others (2014) explain, it is realistic to assume that companies are not able to predict labour problems, disruptions in their supply chains or organizational shocks when they make decisions about their process investments. Similarly, this paper maintains the hypothesis that process innovations are exogenous.
} 
Thus, growth in the prices of both products appears in the error term, and the correlation between the prices of the new products $\left(\pi_{2}\right)$ and $g_{2}$ has the potential to create an additional bias in product innovation. As in the previous case, this will be manifested as an attenuation bias in the estimation of $\beta$ using the OLS method. To deal with the measurement problem, we have followed Harrison and others (2014) and used instrumental variables correlated with real growth in the manufacture of new products, but not with nominal growth.

According to Harrison and others (2014), using the nominal sales growth rate is also bound to affect interpretation of the process innovation results. The rate of price growth for existing products may be affected by the efficiency impact of process innovations, since efficiency gains are manifested in prices. In other words, it is possible that $\pi_{1}=\pi_{0}+\gamma \alpha_{1} d$, where $\gamma$ is a parameter measuring price pass-through in an interval $[0,1]$. Replacing this expression in equation (5) gives:

$$
l-g_{1}=\alpha_{0}+(1-\gamma) \alpha_{1} d+\beta g_{2}+\left(-\pi_{1}+\beta \pi_{2}+v\right)
$$

The lack of price data at the firm level means that the true displacement effect may be underestimated. How severe this underestimation is will depend on the extent to which higher efficiency due to innovation passes through to prices. If pass-through were high, with $\gamma \sim 1$, process innovations could prove non-significant. To correct this problem, we have followed the strategy developed by Harrison and others (2014), which consists in approximating prices at the firm level $\left(\pi_{1}\right)$ using deflators at the level of the relevant sector of activity $(\pi)$. Thus, the estimation consists in:

$$
l-\left(g_{1}-\pi\right)=\alpha_{0}+\alpha_{1} d+\beta g_{2}+\left(-\left(\pi_{1}-\pi\right)-\beta \pi_{2}+v\right)
$$

If prices at the firm level do not deviate much from the deflators at the sectoral level $\left(\pi \approx \pi_{1}\right)$, it will be possible to obtain more consistent estimators of the displacement effect caused by process innovations for existing products.

Innovation can have different effects on the creation of skilled and unskilled employment. If it is skill-biased, as a number of theoretical studies (Card and DiNardo, 2002; Acemoglu, 1998, among others) have argued, higher levels of innovation may be associated with lower rates of growth in unskilled employment and higher growth in skilled employment.

To analyse the effect of innovation on the composition of employment, the approach described in the previous section is followed and a variant of equation (6) is used. Specifically, the growth rate of each type of employment, skilled $\left(l^{s}\right)$ and unskilled $\left(l^{u s}\right)$, is estimated separately.

$$
\begin{gathered}
l_{i t}^{s}-\left(g_{1 i t}-\pi\right)=\alpha_{0}^{s}+\alpha_{1}^{s} d_{i t}+\beta^{s} g_{2 i t}+\varepsilon_{i t} \\
l_{i t}^{u s}-\left(g_{1 i t}-\pi\right)=\alpha_{0}^{u s}+\alpha_{1}^{u s} d_{i t}+\beta^{u s} g_{2 i t}+\eta_{i t}
\end{gathered}
$$

The dependent variable is employment growth (for each skill type) minus the real increase in sales of existing products. Equations (7) and (8) can be used to analyse how each type of innovation separately influences the growth of the different employment types. Similarly, and for the reasons already described, instrumental variables are used. 


\section{Database and descriptive statistics}

To model the relationship between innovation and employment growth, use was made of the ENDEl with information on Argentine manufacturing firms for the period 2010-2012. This database is the product of a joint study by the Ministry of Science, Technology and Productive Innovation (MINCyT) and the Ministry of Labour, Employment and Social Security (MTEySS) of Argentina. The form prepared for the ENDEI was based on the Oslo and Bogotá Manual for collecting information on innovation activities in firms. The sampling frame was composed of private firms with 10 or more workers registered in the Argentine Integrated Social Security System (SIPA). From this, a sample stratified by branch of activity and size was selected. Some firms were incorporated by stratified random sampling and others by forced inclusion. The population distribution for which the survey was designed was 18,900 firms, while 3,995 cases were selected for the sample, with a response rate of 92\% (3,691 cases). The ENDEl contains detailed information on the characteristics of firms, their innovation activities and their employment (in terms of both evolution and composition), making it possible to calculate the percentage of sales of new products and thence nominal growth in sales of new products $\left(g_{2}\right) \cdot{ }^{9}$

To describe the results of this database, a taxonomy of firms was constructed by types of innovation behaviour: product innovators, process innovators (only) and non-innovators. ${ }^{10}$ As in Harrison and others (2014), firms that innovated (in both processes and products) were classified as product innovators. This decision was based on the fact that firms innovating in both categories behave more like product innovators than those that are only process innovators, or those making organizational changes.

Table 1 presents a series of descriptive statistics for the total sample, stratified by sectoral technology content and size. Where the innovation performance of these firms is concerned, between 2010 and 2012 about $50 \%$ stated that they had introduced some product innovation, just over $7 \%$ introduced process innovations only and about $43 \%$ did not introduce any new products or processes. Small firms in high-technology sectors are overrepresented in the category of non-innovative companies. On the other hand, medium-sized and large firms in low-technology sectors are overrepresented among the innovators.

With regard to employment growth, it may be mentioned that whilst non-innovative firms destroyed jobs, those that introduced an innovation grew strongly enough to offset this decline, so that employment grew overall. This result is quite robust when different types of sectors or company sizes are compared. The results are similar for firms that are both process and product innovators, without there being any a priori reason to believe that process innovation is detrimental to employment, suggesting the presence of compensation effects. In the case of product innovations, sales of existing products show positive growth rates, with growth in new products coming on top of this.

The ENDEl can also be used to analyse employment growth by skill level. There was net destruction of low-skilled jobs among non-innovative firms, this being particularly intensive among low-technology firms. At the same time, there was subdued growth in high-skilled employment in innovative firms. Second, skilled employment in innovative firms grew faster than low-skilled employment, a finding that does not change when the technology content of the sector to which the firm belongs or its size is controlled for. Third, when the entirety of firms is analysed, what stands out is the growth of skilled employment among small low-technology firms. Low-skilled employment, meanwhile, only grew strongly among low-technology firms.

\footnotetext{
9 The ENDEl includes a question about the proportion of sales at the end of the period that correspond to product innovations. This proportion is called s. It also includes information about nominal sales growth $(g)$. Given that sales of new products at the beginning of the period are by definition zero, it can easily be deduced that nominal growth in sales of new products can be calculated as $g_{2}=s(1+g)$.

10 Includes organizational and marketing-related changes.
} 
Table 1

Product and process innovators: growth in employment, sales, productivity, employment and prices, 2010-2012a

(Percentages)

\begin{tabular}{|c|c|c|c|c|c|}
\hline & \multirow{2}{*}{ Total } & \multicolumn{2}{|c|}{ Technology content ${ }^{b}$} & \multicolumn{2}{|c|}{ Size $^{c}$} \\
\hline & & Low & High & Small & Medium and large \\
\hline \multicolumn{6}{|l|}{ Number of firms } \\
\hline Non-innovators (process or product) & 43.3 & 2.3 & 52.6 & 46.2 & 19.2 \\
\hline Process innovators only & 7.4 & 5.6 & 7.9 & 6.8 & 13.2 \\
\hline Product innovators & 49.3 & 92.1 & 39.5 & 47.1 & 67.5 \\
\hline \multicolumn{6}{|l|}{ Employment growth $^{d}$} \\
\hline Non-innovators (process or product) & -1.9 & -2.6 & -1.9 & -1.7 & -6.6 \\
\hline Process innovators only & 2.4 & 10.7 & 1.0 & 4.0 & -4.6 \\
\hline Product innovators & 6.6 & 4.2 & 7.9 & 7.1 & 3.5 \\
\hline All firms & 2.6 & 4.4 & 2.2 & 2.9 & 0.5 \\
\hline \multicolumn{6}{|l|}{ low-skillede } \\
\hline Non-innovators (process or product) & -2.2 & -3.1 & -2.2 & -2.0 & -6.3 \\
\hline Process innovators only & 1.7 & 9.9 & 0.4 & 3.1 & -4.6 \\
\hline Product innovators & 6.7 & 3.9 & 8.2 & 7.1 & 4.5 \\
\hline All firms & 2.5 & 4.1 & 2.1 & 2.6 & 1.2 \\
\hline \multicolumn{6}{|l|}{ high-skilled } \\
\hline Non-innovators (process or product) & 0.4 & -0.4 & 0.4 & 0.4 & 0.1 \\
\hline Process innovators only & 4.2 & 9.0 & 3.4 & 2.6 & 10.7 \\
\hline Product innovators & 5.5 & 5.8 & 5.3 & 5.2 & 6.9 \\
\hline All firms & 3.2 & 5.8 & 2.6 & 2.8 & 6.1 \\
\hline \multicolumn{6}{|l|}{ Sales growth } \\
\hline Non-innovators (process or product) & 22.8 & 18.2 & 22.9 & 23.2 & 16.1 \\
\hline Process innovators only & 23.3 & 24.9 & 23.0 & 24.6 & 17.5 \\
\hline Product innovators & 24.3 & 22.4 & 25.4 & 24.6 & 22.7 \\
\hline \multicolumn{6}{|l|}{ Sales are divided into: } \\
\hline old products & 7.8 & 5.0 & 9.3 & 7.9 & 6.8 \\
\hline new products & 16.5 & 17.4 & 15.9 & 16.6 & 15.9 \\
\hline All firms & 23.6 & 22.5 & 23.9 & 23.9 & 20.8 \\
\hline
\end{tabular}

Source: Prepared by the authors, on the basis of data from the Employment and Innovation Dynamics National Survey (ENDEI).

a The statistics reported are from the expanded ENDEl.

b Low-technology: firms whose R\&D intensity relative to sales is below the sample mean; high-technology: firms whose R\&D intensity relative to sales is above the sample mean.

c Small firms: up to 25 employees; medium-sized and large firms: 26 or more employees.

d Statistics on firms are reported with data for total, skilled and unskilled employment. Thus, the totals may differ from those reported earlier.

e High-skilled: employees with a university or tertiary degree; low-skilled: employees with less than a university or tertiary degree.

\section{Results}

The purpose of the first exercise carried out is to obtain a naive estimate using OLS (see table 2). The specification is based on regressing employment growth with growth in deflated total sales, binary variables for different types of innovation (process and product) and sectoral indicators. The results show that employment growth rates are positively affected by real sales growth as well as process or product innovations in each of the specifications presented.

The methodological discussion indicates that direct estimation by classical least squares (CLS) yields biased results if: (i) the innovation results are correlated with productivity shocks, or (ii) part of the growth in prices ends up being captured by the error term. While the first scenario can be dismissed because bounded rationality prevents firms from anticipating unforeseen productivity shocks, the second 
scenario needs to be considered. The estimates presented are therefore inconsistent, although they show partial correlations that are very informative for describing the data, but not for identifying the effect of innovation on employment growth.

Table 2

Naive estimates of the relationship between innovation and employment, all firms ${ }^{\mathrm{a}} \mathrm{b}$

\begin{tabular}{|c|c|c|c|}
\hline & (1) & (2) & (3) \\
\hline \multirow[t]{2}{*}{ Process innovator only (not product innovator) } & -0.733 & $5.605^{\star \star}$ & \\
\hline & $(1.990)$ & $(2.134)$ & \\
\hline \multirow[t]{2}{*}{ Product innovator only (not process innovator) } & 0.724 & & $7.055^{\star \star}$ \\
\hline & $(1.785)$ & & $(1.916)$ \\
\hline \multirow[t]{2}{*}{ Product and process innovator } & $6.338^{* \star}$ & & \\
\hline & $(1.059)$ & & \\
\hline \multirow[t]{2}{*}{ Product innovator } & & $6.464^{\star \star}$ & \\
\hline & & $(1.052)$ & \\
\hline \multirow[t]{2}{*}{ Process innovator } & & & $6.232^{\star *}$ \\
\hline & & & $(1.062)$ \\
\hline \multirow[t]{2}{*}{ Real sales growth } & $0.388^{\star \star}$ & $0.388^{\star *}$ & $0.388^{* *}$ \\
\hline & $(0.075)$ & $(0.075)$ & $(0.075)$ \\
\hline \multirow[t]{2}{*}{ Constant } & $-6.309^{\star *}$ & $-6.307^{\star *}$ & $-6.308^{* *}$ \\
\hline & $(0.996)$ & $(0.996)$ & $(0.996)$ \\
\hline Observations & 3.517 & 3.517 & 3.517 \\
\hline R squared & 0.164 & 0.164 & 0.164 \\
\hline H0: Product and process $=$ Process only & 0.00284 & & \\
\hline H0: Product and process = Product only & 0.0116 & & \\
\hline
\end{tabular}

Source: Prepared by the authors, on the basis of data from the Employment and Innovation Dynamics National Survey (ENDEI).

a Robust standard errors in brackets.

b Statistical significance levels: ${ }^{\star *} p<0.01,{ }^{*} p<0.05,{ }^{\star * \star} p<0.1$.

The identification strategy consists in using instruments that are correlated with the product innovation results whilst being orthogonal to the error term. Two instruments are proposed: (i) access to new markets as a result of the innovations brought in by the firm and (ii) knowledge (not necessarily use) of public innovation support instruments. ${ }^{11}$ An instrument must meet two conditions to be valid. The first is known as the orthogonality condition and holds that the instrument should not be correlated with the error term. In the context of the present study, this implies that it must be orthogonal to (or conditionally independent of) growth in new product prices. In relation to the first instrument, access to new markets does not imply a specific direction for price growth: a higher market share could entail lower prices; likewise, the introduction of a new product could lead to an increase in prices. In relation to the second instrument, the identification strategy is based on the implausibility of the correlation between knowledge of public programmes supporting innovation and growth in new product prices (De Elejalde, Giuliodori and Stucchi, 2011). At the same time, once the sector, size and time-fixed productivity shocks are controlled for, both instruments can also be considered exogenous. First, since information is costly to acquire, only the largest and most productive companies could make the necessary investment. These effects are taken into account by controlling for size and for productivity fixed effects. Second, access to new markets is usually correlated with the size of firms and the sector they are in. These effects are controlled for by incorporating sector and size fixed effects.

The second requirement is known as a relevance condition and requires non-trivial correlation between the proposed instrument and the endogenous variable. This condition can be subjected to a test of joint significance on the instruments proposed in the first stage of the regression. Stock, Wright and Yogo (2002) recommend an F-statistic value greater than 10 to avoid problems of weak instruments that could introduce biases into the instrumental variables estimation.

\footnotetext{
11 In both cases, binary variables are used to determine access to new markets or knowledge of public instruments.
} 
Tables 3 and 4 present these results, controlled for by size and sectoral technology content. In neither case are there found to be effects on employment due to the introduction of process innovations in employment. As highlighted in the literature, there is a positive effect on employment from the introduction of products. Interestingly, the data indicate that new products are produced more efficiently than existing ones (i.e. the $g_{2}$ coefficient is less than 1 ), so employment growth is associated with the expansion of innovations in a context of expanding demand. The negative coefficient of the constant suggests productivity improvements in the manufacture of existing products. In the case of SMEs, although they show greater efficiency for new products than for existing ones, the possibility of this coefficient being equal to 1 cannot be ruled out.

Table 3

Employment growth by size: instrumental variables estimation ${ }^{\text {a b c d }}$

\begin{tabular}{|c|c|c|c|}
\hline Variable & $\begin{array}{c}(1) \\
\text { [IV-Total] }\end{array}$ & $\begin{array}{c}(2) \\
\text { [IV-Small] }\end{array}$ & $\begin{array}{c}(3) \\
\text { [IV-Medium-sized and large] }\end{array}$ \\
\hline \multirow[t]{2}{*}{ Sales growth from new products } & $0.640^{\star \star}$ & $0.829^{\star \star}$ & $0.608^{\star *}$ \\
\hline & $(0.030)$ & $(0.062)$ & $(0.034)$ \\
\hline \multirow[t]{2}{*}{ Process innovator $(d)$} & -2.063 & -0.926 & -2.210 \\
\hline & $(1.854)$ & $(2.421)$ & (2.365) \\
\hline \multirow[t]{2}{*}{ Constant } & $-7.182^{\star \star}$ & $-6.023^{*}$ & $-8.026^{\star \star}$ \\
\hline & $(1.747)$ & $(2.577)$ & $(2.116)$ \\
\hline Observations & 3.517 & 729 & 2.788 \\
\hline R squared & 0.164 & 0.294 & 0.151 \\
\hline Sector dummies & Yes & Yes & Yes \\
\hline Wu-Hausman test & 2.256 & 2.550 & 1.031 \\
\hline$p$-value & 0.133 & 0.111 & 0.310 \\
\hline Sargan test & 128.2 & 7.441 & 109.6 \\
\hline$p$-value & 0 & 0.00638 & 0 \\
\hline
\end{tabular}

Source: Prepared by the authors, on the basis of data from the Employment and Innovation Dynamics National Survey (ENDEI).

a Robust standard errors in brackets.

b Statistical significance levels: ${ }^{\star \star} p<0.01,{ }^{\star} p<0.05,{ }^{\star * \star} p<0.1$.

c All estimates include two-digit industry dummies as additional controls.

d Small firms: up to 25 employees; medium-sized and large firms: 26 or more employees.

Table 4

Employment growth by technology content: instrumental variables estimationabcd

\begin{tabular}{lccc}
\hline Variable & $\begin{array}{c}(1) \\
{[I V-T o t a l]}\end{array}$ & $\begin{array}{c}(2) \\
\text { [IV-Low-technology] }\end{array}$ & $\begin{array}{c}(3) \\
{[\text { IV-High-technology] }}\end{array}$ \\
\hline Sales growth from new products & $0.640^{\star *}$ & $0.538^{* *}$ & $0.658^{\star *}$ \\
\cline { 2 - 4 } & $(0.030)$ & $(0.048)$ & $(0.038)$ \\
\hline Process innovator $(d)$ & -2.063 & -2.849 & -1.810 \\
\hline Constant & $(1.854)$ & $(4.229)$ & $(2.063)$ \\
\hline Observations & $-7.182^{\star *}$ & -1.410 & $-8.084^{\star *}$ \\
\hline R squared & $(1.747)$ & $(3.899)$ & $(1.945)$ \\
\hline Sector dummies & 3.517 & 767 & 2.750 \\
\hline Wu-Hausman test & 0.164 & 0.194 & 0.148 \\
\hline$p$-value & Yes & Yes & 1.033 \\
\hline Sargan test & 2.256 & 1.334 & 0.25 \\
\hline$p$-value & 0.133 & 0.248 & 85.98 \\
\hline
\end{tabular}

Source: Prepared by the authors, on the basis of data from the Employment and Innovation Dynamics National Survey (ENDEI).

a Robust standard errors in brackets.

b Statistical significance levels: ${ }^{* \star} p<0.01,{ }^{*} p<0.05,{ }^{* * \star} p<0.1$.

c All estimates include two-digit industry dummies as additional controls.

d Low-technology: firms whose R\&D intensity relative to sales is below the sample mean; high-technology: firms whose R\&D intensity relative to sales is above the sample mean. 
Combining these categorizations, table 5 presents an estimation differentiated by size and sectoral technology intensity. Although the results are similar to those presented in the two previous tables, it can be observed that medium-sized firms, especially those operating in high-technology sectors, show less of an efficiency gain when they replace existing products with new products in their portfolios. At the same time, it is interesting to note that firms operating in low-technology sectors (as seen in table 5) do not show productivity gains associated with expanding demand.

Table 5

Employment growth by size and technology content: instrumental variables estimation a b c d e

\begin{tabular}{lccccc}
\hline Variables & $\begin{array}{c}(1) \\
{[I V-T o t a l]}\end{array}$ & $\begin{array}{c}(1) \\
\text { [Small and } \\
\text { low-technology] }\end{array}$ & $\begin{array}{c}(2) \\
\text { [Small and } \\
\text { high-technology] }\end{array}$ & $\begin{array}{c}\text { (3) } \\
\text { [Medium-sized } \\
\text { and large and } \\
\text { low-technology] }\end{array}$ & $\begin{array}{c}\text { (4) } \\
\text { [Medium-sized } \\
\text { and large and } \\
\text { high-technology] }\end{array}$ \\
\hline Sales growth from new products & $0.640^{* *}$ & $0.522^{* *}$ & $0.617^{* *}$ & $0.639^{* *}$ & $0.899^{* *}$ \\
\cline { 2 - 6 } & $(0.030)$ & $(0.054)$ & $(0.043)$ & $(0.113)$ & $(0.076)$ \\
\hline Process innovator $(d)$ & -2.063 & -4.236 & -1.601 & 1.549 & -1.950 \\
\hline Constant & $(1.854)$ & $(5.688)$ & $(2.603)$ & $(5.244)$ & $(2.682)$ \\
\hline Observations & $-7.182^{* *}$ & -1.652 & $-8.935^{* *}$ & -1.786 & $-6.994^{*}$ \\
\hline R squared & $(1.747)$ & $(4.969)$ & $(2.330)$ & $(5.219)$ & $(2.883)$ \\
\hline Sector dummies & 3.517 & 580 & 2.208 & 187 & 542 \\
\hline Wu-Hausman test & 0.164 & 0.185 & 0.133 & 0.328 & 0.319 \\
\hline$p$-value & Yes & Yes & Yes & Yes & Yes \\
\hline Sargan test & 2.256 & 0.479 & 0.382 & 0.405 & 2.903 \\
\hline$p$-value & 0.133 & 0.489 & 0 & 0.526 & 0.0118 \\
\hline
\end{tabular}

Source: Prepared by the authors, on the basis of data from the Employment and Innovation Dynamics National Survey (ENDEI).

a Robust standard errors in brackets.

b Statistical significance levels: ${ }^{\star \star} p<0.01,{ }^{*} p<0.05,{ }^{* \star *} p<0.1$.

c All estimates include two-digit industry dummies as additional controls.

d Low-technology: firms whose R\&D intensity relative to sales is below the sample mean; high-technology: firms whose R\&D intensity relative to sales is above the sample mean.

e Small firms: up to 25 employees; medium-sized and large firms: 26 or more employees.

\section{Innovation and its impacts on employment composition (quality)}

This section presents the results of the estimates of equations (7) and (8), controlling for fixed effects at the sectoral level. As in the previous section, the strategy applied is based on the use of instrumental variables. Taking into account the validity of the instruments used, the same instruments as were presented in the previous sections are employed again.

The results presented in table 6 suggest some interesting patterns as regards impacts on employment composition. First, the coefficients associated with product innovation are significant and show a tendency to improve efficiency when new products come to be manufactured. Second, coefficients associated with $g_{2}$ do not differ between employment skill types, implying that product innovation has no specific bias. Where process innovation is concerned, although the coefficients are not significant, a higher numerical value is observed for skilled employment (albeit with more imprecise coefficients). It is worth noting that improvements in trend productivity (captured by the constant) exhibit greater destruction of high-skilled employment. 
Table 6

Employment growth by skill level: instrumental variables estimation ${ }^{\mathrm{b}} \mathrm{c}$ de

\begin{tabular}{lccc}
\hline Variable & $(1)$ & $\begin{array}{c}(2) \\
\text { [IV-High-skilled] }\end{array}$ & $\begin{array}{c}(3) \\
\text { [IV-Low-skilled] }\end{array}$ \\
\hline Sales growth from new products & $0.670^{\star \star}$ & $0.560^{\star \star}$ & $0.670^{\star \star}$ \\
\cline { 2 - 4 } & $(0.031)$ & $(0.034)$ & $(0.033)$ \\
\hline Process innovator $(d)$ & -2.401 & -1.533 & -2.816 \\
\hline Constant & $(1.865)$ & $(2.029)$ & $(1.978)$ \\
\hline Observations & $-7.065^{\star *}$ & $-3.801^{\star}$ & $-7.121^{\star *}$ \\
\hline R squared & $(1.760)$ & $(1.915)$ & $(1.867)$ \\
\hline Sector dummies & 3.433 & 3.433 & 3.433 \\
\hline Wu-Hausman test & 0.170 & 0.104 & 0.158 \\
\hline$p$-value & Yes & Yes & Yes \\
\hline Sargan test & 1.801 & 10.64 & 1.057 \\
\hline$p$-value & 0.180 & 0 & 0.304 \\
\hline
\end{tabular}

Source: Prepared by the authors, on the basis of data from the Employment and Innovation Dynamics National Survey (ENDEI).

a Robust standard errors in brackets.

b Statistical significance levels: ${ }^{\star *} p<0.01,{ }^{*} p<0.05,{ }^{* \star}{ }^{*} p<0.1$.

c All estimates include two-digit industry dummies as additional controls.

d High-skilled: employees with a university or tertiary degree; low-skilled: employees with less than a university or tertiary degree.

e Estimates for firms with data on total, skilled and unskilled employment are reported. Thus, the totals may differ from those reported earlier.

The results are similar for small enterprises with different sectoral technological intensities (see tables 7 and 8). First, the $g_{2}$ coefficients for small enterprises are close to 1, especially where low-skilled employment is concerned. This shows that there are no changes in production efficiency when switching from existing products to new products. Second, process innovations have a skilled personnel displacement effect in the case of larger firms.

Table 7

Employment growth by skill level and technology content: instrumental variables estimation ${ }^{\text {a }}$ c d ef

\begin{tabular}{|c|c|c|c|c|c|c|}
\hline \multirow{3}{*}{ Variables } & (1) & (2) & (3) & (4) & (5) & (6) \\
\hline & \multicolumn{3}{|c|}{ Small } & \multicolumn{3}{|c|}{ Medium-sized and large } \\
\hline & [IV-Total] & [IV-High-skilled] & [IV-Low-skilled] & [IV-Total] & [IV-High-skilled] & [IV-Low-skilled] \\
\hline \multirow[t]{2}{*}{ Sales growth from new products } & $0.813^{\star \star}$ & $0.728^{\star \star}$ & $0.818^{\star \star}$ & $0.644^{\star \star}$ & $0.515^{\star \star}$ & $0.644^{\star *}$ \\
\hline & $(0.063)$ & $(0.093)$ & $(0.070)$ & $(0.035)$ & $(0.036)$ & $(0.037)$ \\
\hline \multirow{2}{*}{ Process innovator $(d)$} & -1.006 & 4.327 & -1.634 & -2.764 & $-4.759+$ & -3.145 \\
\hline & $(2.409)$ & (3.575) & $(2.689)$ & $(2.399)$ & $(2.463)$ & $(2.528)$ \\
\hline \multirow[t]{2}{*}{ Constant } & $-5.833^{*}$ & 2.095 & $-5.298+$ & $-7.839^{\star *}$ & $-6.008^{* *}$ & $-8.100^{\star *}$ \\
\hline & $(2.564)$ & $(3.805)$ & $(2.862)$ & $(2.145)$ & $(2.203)$ & $(2.260)$ \\
\hline Observations & 725 & 725 & 725 & 2.708 & 2.708 & 2.708 \\
\hline R squared & 0.291 & 0.141 & 0.256 & 0.157 & 0.105 & 0.148 \\
\hline Sector dummies & Yes & Yes & Yes & Yes & Yes & Yes \\
\hline Wu-Hausman test & 2.332 & 3.117 & 2.366 & 0.681 & 7.340 & 0.169 \\
\hline$p$-value & 0.127 & 0.00497 & 0.124 & 0.409 & 0.00679 & 0.681 \\
\hline Sargan test & 7.672 & 7.892 & 4.344 & 92.39 & 61.60 & 83.98 \\
\hline$p$-value & 0.00561 & 0.0779 & 0.0371 & 0 & 0 & 0 \\
\hline
\end{tabular}

Source: Prepared by the authors, on the basis of data from the Employment and Innovation Dynamics National Survey (ENDEI).

a Robust standard errors in brackets.

b Statistical significance levels: ${ }^{\star \star} p<0.01,{ }^{\star} p<0.05,{ }^{* \star \star} p<0.1$.

c All estimates include two-digit industry dummies as additional controls.

d Small firms: up to 25 employees; medium-sized and large firms: 26 or more employees.

e High-skilled: employees with a university or tertiary degree; low-skilled: employees with less than a university or tertiary degree.

f Estimates for firms with data on total, skilled and unskilled employment are reported. Thus, the totals may differ from those reported earlier. 
Table 8

Employment growth by skill level and size: instrumental variables estimation abc def

\begin{tabular}{|c|c|c|c|c|c|c|}
\hline \multirow{3}{*}{ Variable } & (1) & $(2)$ & (3) & (4) & $(5)$ & (6) \\
\hline & \multicolumn{3}{|c|}{ Low-technology } & \multicolumn{3}{|c|}{ High-technology } \\
\hline & [IV-Total] & [IV-High-skilled] & [IV-Low-skilled] & [IV-Total] & [IV-High-skilled] & [IV-Low-skilled] \\
\hline \multirow[t]{2}{*}{ Sales growth from new products } & $0.613^{\star \star}$ & $0.430^{\star \star}$ & $0.619^{\star \star}$ & $0.664^{\star *}$ & $0.563^{\star \star}$ & $0.665^{\star \star}$ \\
\hline & $(0.051)$ & $(0.057)$ & $(0.057)$ & $(0.039)$ & $(0.042)$ & $(0.041)$ \\
\hline \multirow[t]{2}{*}{ Process innovator $(d)$} & -1.392 & -3.093 & -1.403 & -2.498 & -0.974 & -2.945 \\
\hline & $(4.195)$ & $(4.720)$ & (4.662) & $(2.083)$ & $(2.247)$ & (2.188) \\
\hline \multirow[t]{2}{*}{ Constant } & -2.574 & 5.940 & -2.844 & $-7.702^{\star \star}$ & $-5.337^{\star}$ & $-7.739^{\star \star}$ \\
\hline & $(3.865)$ & $(4.349)$ & (4.295) & $(1.967)$ & $(2.122)$ & $(2.066)$ \\
\hline Observations & 751 & 751 & 751 & 2.682 & 2.682 & 2.682 \\
\hline R squared & 0.212 & 0.110 & 0.188 & 0.150 & 0.092 & 0.143 \\
\hline Sector dummies & Yes & Yes & Yes & Yes & Yes & Yes \\
\hline Wu-Hausman test & 1.071 & 3.702 & 0.535 & 0.631 & 6.496 & 0.349 \\
\hline$p$-value & 0.301 & 0.000621 & 0.465 & 0 & 0.0109 & 0 \\
\hline Sargan test & 19.27 & 11.71 & 15.40 & 80.85 & 59.31 & 71.51 \\
\hline$p$-value & $1.14 \mathrm{e}-05$ & 0.0547 & $8.69 \mathrm{e}-05$ & 0.427 & 0 & 0.555 \\
\hline
\end{tabular}

Source: Prepared by the authors, on the basis of data from the Employment and Innovation Dynamics National Survey (ENDEI).

a Robust standard errors in brackets.

b Statistical significance levels: ** $p<0.01,{ }^{*} p<0.05,{ }^{* \star *} p<0.1$.

c All estimates include two-digit industry dummies as additional controls.

d Low-technology: firms whose R\&D intensity relative to sales is below the sample mean; high-technology: firms whose R\&D intensity relative to sales is above the sample mean.

e High-skilled: employees with a university or tertiary degree; low-skilled: employees with less than a university or tertiary degree.

f Estimates for firms with data on total, skilled and unskilled employment are reported. Thus, the totals may differ from those reported earlier.

\section{Decomposition of the effects of innovation on employment}

The results obtained can be used to break employment growth down into four components. Going by the specification presented in equation (6) and the results obtained using instrumental variables, employment growth for each firm can be written as follows:

$$
l=\left[\sum_{j}\left(\hat{\alpha}_{0}+\hat{\alpha}_{0 j}\right) i n d_{j}\right]+\hat{\alpha}_{1} d+\left[1-1\left(g_{2}>0\right)\right]\left(g_{1}-\pi_{1}\right)+1\left(g_{2}>0\right)\left(g_{1}-\pi_{1}+\hat{\beta} g_{2}\right)+\hat{u}
$$

The first component $\left[\sum_{j}\left(\hat{\alpha}_{0}+\hat{\alpha}_{0 j}\right)\right.$ ind $\left._{j}\right]$ measures the change in employment that is attributable $\left(\widehat{\alpha_{1} d}\right)$ to the (sector-specific) productivity trend in the manufacture of existing products. The second term measures firm-specific productivity growth due to process innovation. The third component $\left[1-1\left(g_{2}>0\right)\right]\left(g_{1}-\pi_{1}\right)$ is the change in employment associated with growth in output of existing products at firms that did not bring new products to market. Lastly, $1\left(g_{2}>0\right)\left(g_{1}-\pi_{1}+\hat{\beta} g_{2}\right)$ gives the net contribution of product innovation (i.e., after allowing new products to be substituted for existing products). The term $\hat{u}$ is a residual component with an average of zero.

Table 9 sets out the results of applying this decomposition on the basis of the descriptive statistics presented in table 1 and the coefficients obtained in the instrumental variables estimation of tables 5 and 6. 
Table 9

Decomposition of total employment in manufacturing industry: instrumental variables estimation, 2010-2012

\begin{tabular}{lcccccc}
\hline & \multirow{2}{*}{ Total } & \multicolumn{3}{c}{ Size } & \multicolumn{2}{c}{ Technology content } \\
\cline { 6 - 7 } \cline { 6 - 7 } & & Small & Medium and large & Low & High \\
\hline Employment growth & 2.2 & 2.5 & 1.6 & 3.8 & 1.8 \\
\hline Productivity trends in the manufacture of old products & -6.9 & -8.1 & -4.7 & 0.0 & -8.0 \\
\hline $\begin{array}{l}\text { Gross effect of process innovation in the manufacture } \\
\text { of old products }\end{array}$ & -0.2 & -0.1 & -0.3 & -0.2 & -0.2 \\
\hline $\begin{array}{l}\text { Contribution of growth in the manufacture of old products } \\
\text { Net contribution of product innovation }\end{array}$ & 4.9 & 5.5 & 2.5 & 0.6 & 6.0 \\
\hline$\quad$ Contribution of existing products (product innovators) & 1.4 & 5.2 & 4.0 & 3.4 & 4.0 \\
\hline$\quad$ Contribution of new products (product innovators) & 3.0 & 3.5 & -0.3 & -4.8 & 2.1 \\
\hline
\end{tabular}

Source: Prepared by the authors, on the basis of data from the Employment and Innovation Dynamics National Survey (ENDEI).

The first component shows that improving productivity for existing products is a significant cause of lower employment for a given level of output. The effects are very large, except in low-technology companies, where the opposite seems to occur.

Although growth in production levels during this period of expansion brings increased demand for employment (the third component), this greater demand is not enough to compensate for the reductions stemming from trend improvements in sectoral productivity. The lowest level of compensation in this regard is observed in firms in low-technology sectors.

For their part, process innovations are responsible for a reduction in employment, which produces a small displacement effect. Drawing on Harrison and others (2014), this effect can be explained in part by underestimation and by the fact that few firms introduce process innovations without product innovations. Thus, while process innovations can lead to large reductions in employment on occasion, they have only a small effect in terms of aggregate changes in employment.

Consequently, it is clear that product innovations are the ones playing the fundamental role in job creation at the firm level. This result is maintained in the whole panel of firms and in the estimates by size and technology content. This is particularly so for small businesses, which would show significant job destruction without this effect.

Table 10 presents the results of applying this decomposition by means of the descriptive statistics presented in tables 1 and 8 , plus the coefficients obtained in the instrumental variables estimation of table 9 .

Table 10

Decomposition of total high- and low-skilled employment in manufacturing industry: instrumental variables estimation, 2010-2012

\begin{tabular}{lccc}
\hline & Total employment & $\begin{array}{c}\text { High-skilled } \\
\text { employment }\end{array}$ & $\begin{array}{c}\text { Low-skilled } \\
\text { employment }\end{array}$ \\
\hline Employment growth & 2.2 & 4.1 & 2.2 \\
\hline Productivity trends in the manufacture of old products & -6.8 & -4.7 & -7.0 \\
\hline Gross effect of process innovation in the manufacture of old products & -0.2 & -0.1 & -0.2 \\
\hline Contribution of growth in the manufacture of old products & 4.9 & 4.9 & 4.9 \\
\hline Net contribution of product innovation & 4.4 & 4.1 & 4.6 \\
\hline$\quad$ Contribution of existing products (product innovators) & 1.4 & 1.4 & 1.4 \\
\hline Contribution of new products (product innovators) & 3.0 & 2.7 & 3.2 \\
\hline
\end{tabular}

Source: Prepared by the authors, on the basis of data from the Employment and Innovation Dynamics National Survey (ENDEI). 
The components explanation yields a scenario similar to the previous one. The destruction of employment attributable to improved productivity in the manufacture of existing products is very considerable (especially in the low-skilled segment). However, it is not fully compensated for by the increase in demand for labour resulting from the growth in production levels, so that it is product innovations that are responsible for net job creation in the period.

\section{Conclusions}

This article has analysed the effect of innovation on the job creation process. In particular, it has attempted to identify the role played by innovation during the latest phase of employment growth in Argentine manufacturing industry. To this end, it applied the model originally proposed by Harrison and others (2014), applying an instrumental variables approach in which use was made of the recently introduced ENDEl with information from the period 2010-2012. The results show that while process innovations are responsible for a small reduction in employment by generating a small displacement effect, compensation effects tend to prevail in the overall outcome. Employment growth is positively affected by product innovations. This result holds for firms of different sizes operating in sectors of different technology intensity. At the same time, new products were found to be manufactured more efficiently than existing products, so employment growth is associated with the expansion of innovations in a context of growing demand. With regard to the effects on the composition of employment, product innovation is found to have no specific bias. The skilled employment displacement effect caused by process innovations is greater in larger firms.

The results provide important inputs for the literature on innovation and employment in Argentina. For the first time, and contrary to what was shown by studies analysing the convertibility period, compensation effects prevailed over mechanisms that displaced jobs following the introduction of innovations. Although empirical data confirm that innovation is a major determinant of growth and productivity at the firm level, the evidence is scant. This paper thus makes an important contribution to the literature by highlighting the leading role played by innovation during the industrial employment expansion phase in the period 2010-2012.

From another perspective, analysing the contribution of work to policy design yields results with implications worth highlighting. In particular, they show that it is essential to understand the relationship between innovation and employment at the firm level to be able to predict how different types of innovation will affect job creation, thus allowing innovation policies to be better designed. At the same time, they show that innovation plays an extremely important role as an engine of employment growth. This study breaks new ground with regard to the technological specificities of each sector and the size of each firm. This poses major challenges for policymakers, as the design of interventions aimed at stimulating growth in employment (especially highly skilled employment) requires the interaction of the industrial and scientific spheres. 


\section{Bibliography}

Acemoglu, D. (1998), "Why do new technologies complement skills? Directed technical change and wage inequality", The Quarterly Journal of Economics, vol. 113, No. 4, Oxford University Press.

Albornoz, F. (2002), "Los efectos de la innovación sobre la calidad y calidad del empleo industrial en Argentina: sustitución importada y una complementariedad trunca", Apertura e innovación en la Argentina: para desconcertar a Vernom, Schumpeter y Freeman, R. Bisang, G. Lugones and G. Yoguel, Buenos Aires, Miño y Dávila.

Card, D. and J. DiNardo (2002), "Skill-biased technological change and rising wage inequality: some problems and puzzles", Journal of Labor Economics, vol. 20, No. 4, Chicago, The University of Chicago Press.

Crespi, G. A. and E. Tacsir (2013), "Effects of innovation on employment in Latin America", MERIT Working Papers, No. 1, Maastricht, United Nations University-Maastricht Economic and Social Research Institute on Innovation and Technology (UNU-MERIT).

De Elejalde, R., D. Giuliodori and R. Stucchi (2011), "Employment generation, firm size and innovation: microeconometric evidence from Argentina", Technical Notes, No. IDB-TN-313, Washington, D.C., Inter-American Development Bank (IDB).

Greenan, N. and D. Guellec (2000), "Technological innovation and employment reallocation", Labour, vol. 14, No. 4, Wiley.

Harrison, R. and others (2014), "Does innovation stimulate employment? A firm-level analysis using comparable micro-data from four European countries", International Journal of Industrial Organization, vol. 35, Amsterdam, Elsevier.

Olley, G. S. and A. Pakes (1996), "The dynamics of productivity in the telecommunications equipment industry", Econometrica, vol. 64, No. 6, New York, The Econometric Society.

Pianta, M. (2006), "Innovation and employment", The Oxford Handbook of Innovation, J. Fagerberg and D. C. Mowery (eds.), Oxford, Oxford University Press.

Roitter, S., A. Erbes and L. Traitemberg (2007), "Determinantes cíclicos y estructurales del comportamiento de las firmas metalmecánicas argentinas frente al empleo durante los noventa", paper presented at the Eighth National Congress of Labour Studies, Buenos Aires, August.

Stock, J., J. H. Wright and M. Yogo (2002), "A survey of weak instruments and weak identification in generalized method of moments", Journal of Business \& Economic Statistics, vol. 20, No. 4, Taylor \& Francis.

Vivarelli, M. (2011), "Innovation, employment and skills in advanced and developing countries: a survey of the literature", Technical Notes, No. IDB-TN-351. Washington, D.C., Inter-American Development Bank (IDB).

Yoguel, G., F. Barletta and M. Novick (2013), "Aportes desde la experiencia y la literatura internacional en materia de innovación y empleo para América Latina: los desafíos de las nuevas tecnologías”, unpublished. 


\section{Annex A1}

\section{Description of variables used}

Table A1.1

Description of variables used

\begin{tabular}{|c|c|}
\hline Variable & Description \\
\hline Total employment growth $(l)$ & $\begin{array}{l}\text { Annualized employment growth between } 2010 \text { and 2012. Calculated as the simple difference } \\
\text { of the logarithm of employment in each year. }\end{array}$ \\
\hline Process innovation only $(d)$ & $\begin{array}{l}\text { Binary variable taking the value } 1 \text { if the firm introduced a process innovation in the manufacture } \\
\text { of old products, or if it introduced an organizational change (without new products). }\end{array}$ \\
\hline \multirow[t]{3}{*}{$\begin{array}{l}\text { Nominal growth in sales } \\
\text { of old products }\left(g_{1}\right)\end{array}$} & $\begin{array}{l}\qquad \ln \left(Y_{12}\right)-\ln \left(Y_{11}\right) \\
\text { where } Y_{12} \text { is the real value of sales of old products in } 2012 \text { and } Y_{11} \text { is the real value of sales } \\
\text { of old products in } 2010 \text {. } \\
\text { Sales of old products are calculated as: }\end{array}$ \\
\hline & Total sales $_{t}-$ pnd $*$ Total sales ${ }_{t}$ \\
\hline & $\begin{array}{l}\text { where pnd is the percentage of sales that are of new products and is sales in the domestic and } \\
\text { external markets. }\end{array}$ \\
\hline Price growth at the sector level $(\pi)$ & $\begin{array}{l}\text { Annualized growth in the producer price index (IPP) of the National Institute of Statistics and Censuses } \\
\text { (INDEC). Calculated as the simple difference between the logarithm of the IPP in } 2012 \text { and the } \\
\text { logarithm of the IPP in } 2010 .\end{array}$ \\
\hline \multirow{3}{*}{$\begin{array}{l}\text { Nominal growth in new product } \\
\text { sale }\left(g_{2}\right)\end{array}$} & $Y_{22} / Y_{11}$ \\
\hline & $\begin{array}{l}\text { where } Y_{22} \text { is the real value of sales of new products in } 2012 \text { and } Y_{11} \text { is the real value of sales } \\
\text { of new products in } 2010 \text {. } \\
\text { Sales of new products are calculated as: }\end{array}$ \\
\hline & pnd $*$ Total sales $_{t}$ \\
\hline $\begin{array}{l}\text { Access to new markets } \\
\text { in consequence of innovation }\end{array}$ & $\begin{array}{l}\text { Binary variable taking the value } 1 \text { if the firm stated it had entered a new external market } \\
\text { in consequence of an innovation made between } 2012 \text { and } 2010 \text {. }\end{array}$ \\
\hline $\begin{array}{l}\text { Knowledge of the existence of public } \\
\text { programmes supporting innovation }\end{array}$ & $\begin{array}{l}\text { Binary variable taking the value } 1 \text { if the firm stated it was aware of the existence of public programmes } \\
\text { supporting innovation, irrespective of whether it had applied for such support. }\end{array}$ \\
\hline
\end{tabular}

Source: Prepared by the authors. 